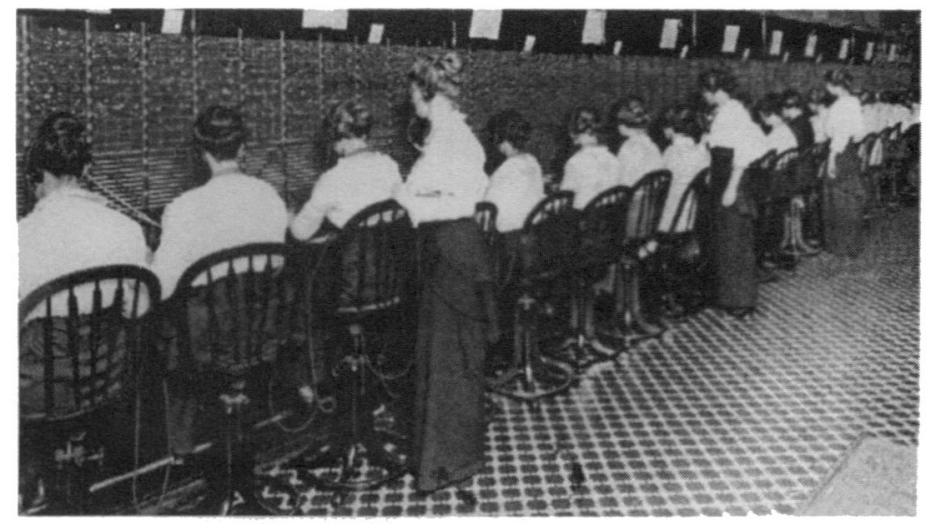

\title{
Race on the Line
}

Gender, Labor, and Technology in the Bell System, 1880-1980

\section{VENUS GREEN 352 pages. 37 b8w photos, paper $\$ 19.95$}

The first book to address the convergence of race, gender, and technology in the telephone industry, Race on the Line presents a hundred year history of telephone operators and their work processes, from the invention of the telephone in 1876 to the period immediately before the break-up of the American Telephone and Telegraph Company in 1984.

Green-a former Bell System employee and current labor historian-shows how, as technology changed from a manual process to a computerized one, sexual and racial stereotypes enabled management to manipulate both the workers and the workplace.

"Race on the Line is an extraordinary achievement. It sets a new standard for understanding the impact of race, gender, and technological change on the labor process in American society."-Joe W. Trotter, author of The African American Experience

\section{Duke University Press}

www.dukeupress.edu or toll-free 1-888-651-0122 


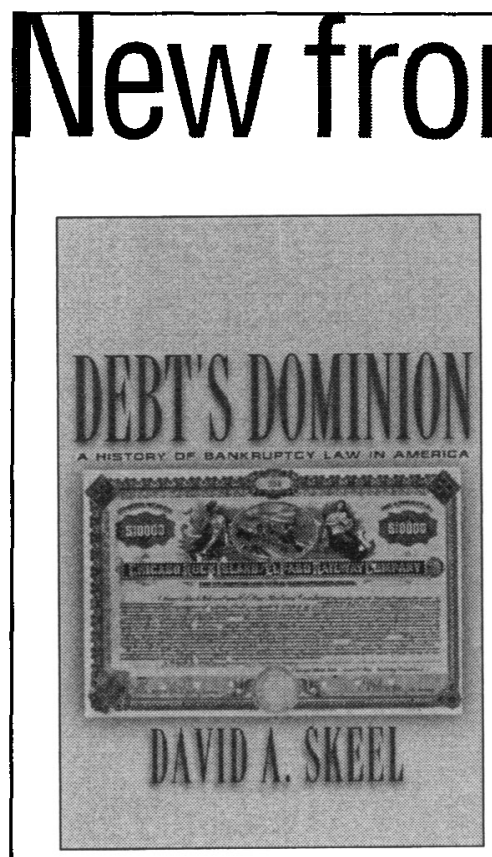

\title{
Debt's Dominion
}

A History of Bankruptcy Law in America David A. Skeel, Jr.

Why has America's legal system evolved to allow both corporate and individual debtors greater control over their fate than imaginable elsewhere? Masterfully probing the political dynamics behind this question, David Skeel here provides the first complete account of the remarkable journey American bankruptcy law has taken from its beginnings in 1800 .

"Skeel's story is startlingly different from traditional accounts and shows how the forces that bring about legislative change are more subtle than commonly understood."-Douglas G. Baird, University of Chicago

Cloth $\$ 35.00$ ISBN 0-691-08810-1

New in paperback

\section{Financing the American Dream}

A Cultural History of Consumer Credit Lendol Calder

"A broadly researched book on the history of consumer credit that breaks new ground and revises prevailing views.... This finely written volume is a major contribution."-Choice

"Financing the American Dream is easily the best writing I have encountered in some time. The language simply flows. I wish everyone could write so well." - The Journal of Economic History

Paper \$18.95 ISBN 0-691-07455-0

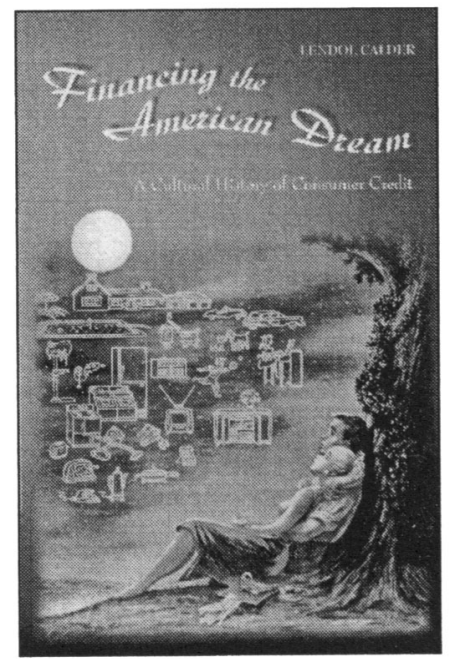

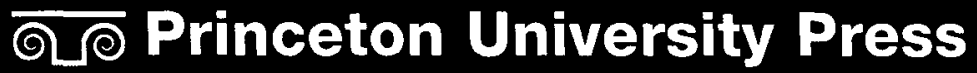

\author{
800-777-4726 • WWW.PUP.PRINCETON.EDU
}



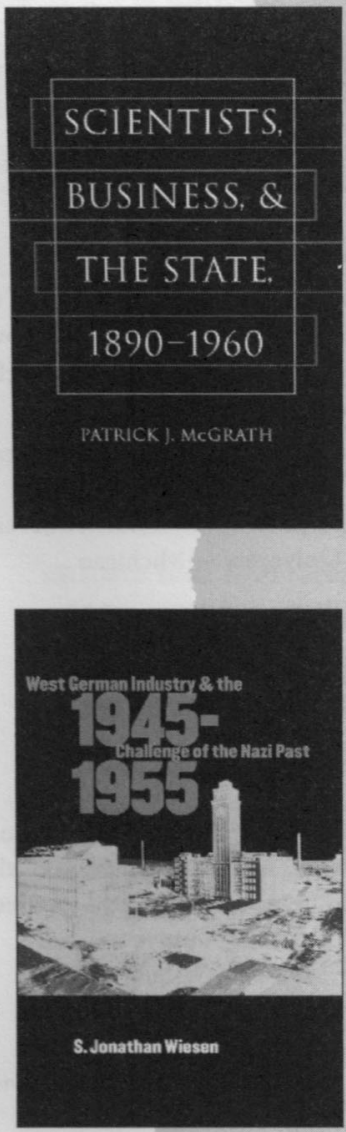

THE UNIVERSITY OF NORTH CAROLINA PRESS at bookstores or $800-848-6224$ | www.uncpress.unc.edu

\section{Scientists, Business,} and the State, 1890-1960 PATRICK J. MCGRATH

The making of the modern military-industrial complex

"Documents, in a compelling and readable fashion, how the notable 19th-century ideal of science in the service of the state led to the triumph of 'scientific militarism' in the Cold War."-Gregg Herken, author of The Winning Weapon

"Rich with insight and, even better, constructively argumentative."-Larry Owens, University of Massachusetts

Luther Haptwell Hodges Series on Business, Society, and the State

Approx. 296 pp. \$39.95 cloth

\section{West German Industry and the Challenge of the Nazi Past, 1945-1955}

\section{S. JONATHAN WIESEN}

How West German industrialists rehabilitated their tarnished image

"A major contribution to the literature on German business and National Socialism.... Sound and judicious... free of ideology and pointless recrimination." -Gerald D. Feldman, University of California, Berkeley 352 pp. $\$ 39.95$ cloth

\section{The Business of Genocide}

The SS, Slave Labor, and the Concentration Camps MICHAEL THAD ALLEN

The bureaucrats behind the Nazi slave labor camps

"Convincingly exposes as entirely false the alleged dichotomy between apolitical, naive, task-absorbed technocrats and ideologically driven, highly politicized Nazi fanatics."-Christopher Browning, University of North Carolina at Chapel Hill Approx. 448 pp. $\$ 39.95$ cloth Available March 2002 


\section{THE BOUCHAYERS OF GRENOBLE AND FRENCH INDUSTRIAL ENTERPRISE, 1850-1970 \\ Robert J. Smith}

"This is an excellent piece of historical work. It successfully combines family and economic history to demonstrate the importance of entrepreneurial decision-making and the crucial role of cultural factors in shaping these decisions."--Robert Forster, The Johns Hopkins University

$\$ 39.95$ hardcover

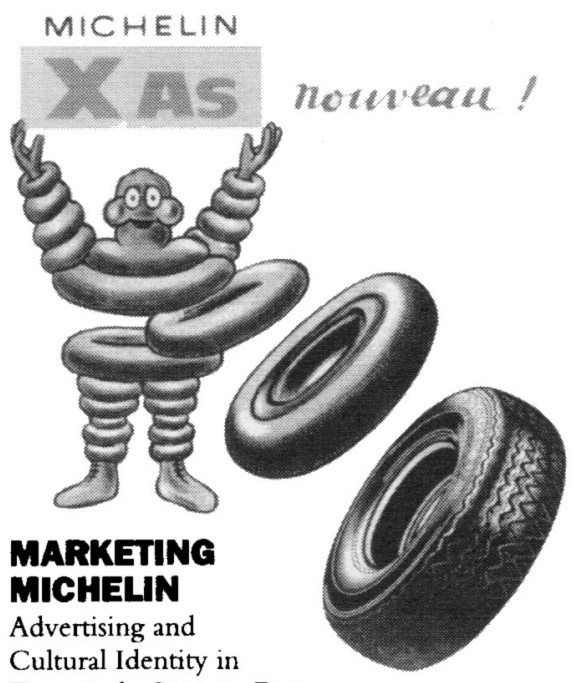

Twentieth-Century France

Stephen L. Harp

One of the world's largest tire makers, Michelin is also a uniquely French company, one that throughout its history has closely identified itself with the country's people and culture. Stephen Harp provides a provocative history of the company and its innovative advertising campaigns between 1898, when Bibendum-the company's iconic "Michelin Man"-was first introduced, to 1940 , when France fell to the Nazis.

\section{maKING AND SELLING caRS}

Innovation and Change in the U.S.

Automotive Industry

\section{James $\boldsymbol{M}$. Rubenstein}

James Rubenstein documents the story of the automotive industry, which, despite its power, is an industry constantly struggling to redefine itself and assure its success.

"No one has actually performed the service of covering the entire U.S. motor vehicle industry in great detail-until now." - Sean P. McAlinden, University of Michigan

$\$ 45.00$ hardcover

\section{HENRY R. LUCE AND THE RISE OF THE AMERICAN NEWS MEDIA}

James L. Baughman

"Despite its brevity, this profile manages to place Luce within the broader context of the twentieth-century news media, and to assess his significance as an innovative journalist. Baughman writes in a refreshing style that (given its subject) is appropriately concise, knowledgeable, and often irreverent." —Donald A. Ritchie, Business History Review $\$ 18.95$ paperback

\section{COMMERCE IN RUSSIAN URBAN CULTURE, 1861-1914 edited by William Craft Brumfield, Boris V. Anan'ich, and Yuri A. Petrov}

Commerce in Russian Urban Culture, 1861-1914 examines the relation between the entrepreneurial world, especially business and banking, and the cultural milieu of Russia.

Woodrow Wilson Center Press

$\$ 49.50$ hardcover

$\$ 39.95$ hardcover

JOHNS HOPKINS

The Johns Hopkins University Press • 1-800-537-5487• www.jhupbooks.com 


\section{AGRICULTURAL HISTORY}

\section{The Quarterly Journal of the Agricultural History Society}

S

ince its inception, the Agricultural History Society has recognized the roles of agriculture and rural life in shaping the political, economic, social, cultural, and historical profiles of different countries of the world. The Society's preeminent place in the study of rural life ensures that Agricultural History, the AHS's official quarterly since 1927 , is considered the international journal of record for the field. A platform for innovative research in national and international agricultural and rural history, the journal publishes articles on rural life, broadly conceived, as well as on institutions and organizations, and considers a wide range of the politics, science, and technologies that have influenced the development of agriculture and rural life.

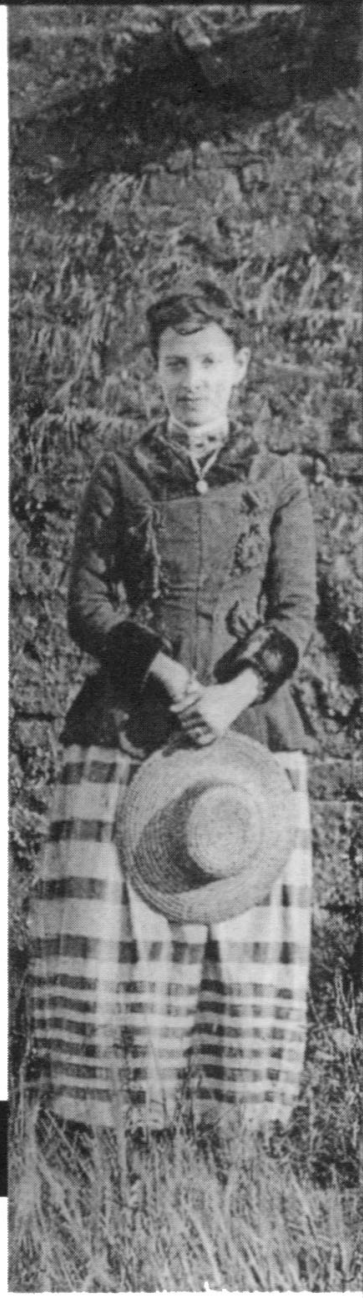

Join the Agricultural History Society today
subscribing to Agricultural History today at www.ucpress.edu/journals/ah, I'd like to join the Agricultural History Society and receive a quarterly subscription to Agricultural History.

Individual: $\$ 35 \$ 29.75$

Student: $\quad \$ 20 \quad \$ 17.00$ (enclose copy of ID)

Institution: $\$ 110 \$ 93.45$ 


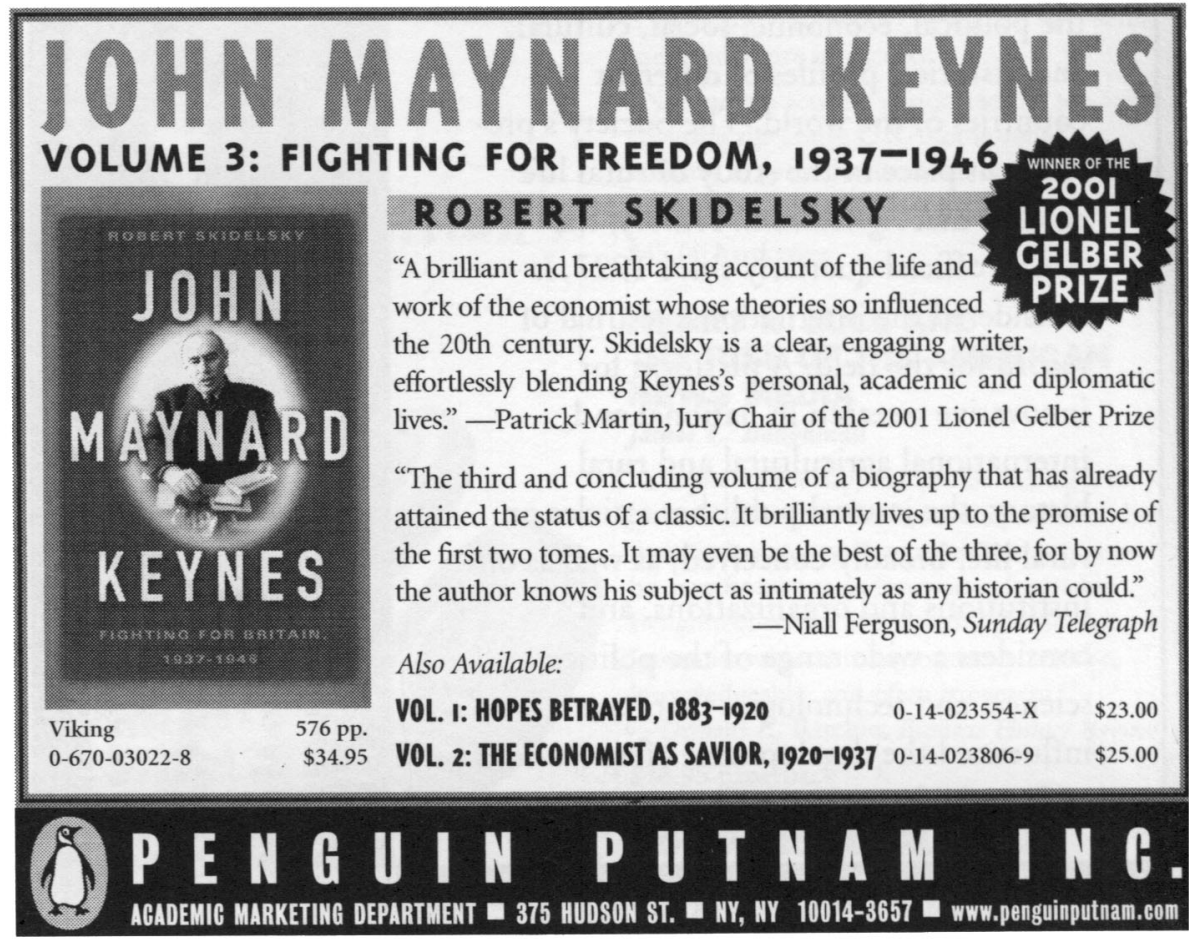



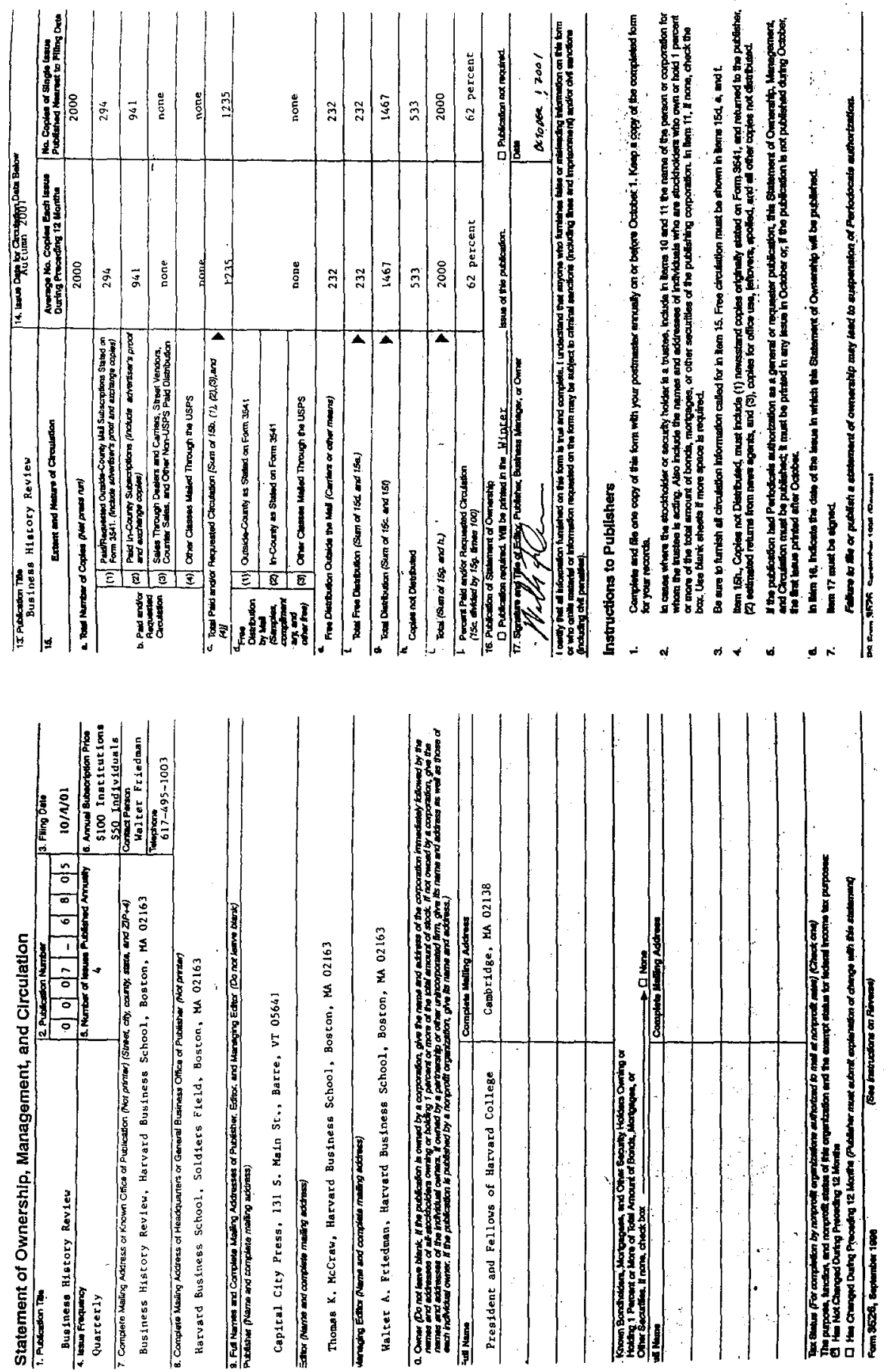


\section{GUIDELINES FOR CONTRIBUTORS}

\section{GENERAL INFORMATION}

Manuscripts are considered for publication on the understanding that they are not concurrently under consideration elsewhere and that the material--in substance as well as formhas not been previously published.

Three copies of the manuscript should be submitted.

Authors should identify themselves only on a separate title page that provides name, mailing address, and telephone number. Authors must also remember not to identify themselves in the body of the manuscript; specifically, references to their own work in the text should be in the third person, and citations should be written without possessive pronouns—not "See my ...."

Potential contributors should initially submit hard copy, not diskettes, but it will save considerable work for all parties in the event of acceptance if authors follow a few rules from the beginning:

- In general, use as few formatting commands as possible.

- Left justify text.

- Do not hyphenate words at the end of lines.

- ALL material-including extracted quotations and notes-must be double spaced.

- Notes should be numbered consecutively and citations should be placed as footnotes or endnotes formatted as indicated by The Chicago Manual of Style (1993).

- Each table and figure must be accompanied by a complete source.

Each article should be accompanied by an abstract of 75 to 100 words outlining the main point(s) of the paper and placing the article in context. Subheads should be used to divide the manuscript into three or four sections (or more, depending on length). We do not have an upper or lower page limit, but articles usually run between 25 and 50 typescript pages, including notes and other material.

We are always eager to publish illustrations, but authors should not include originals of illustrative materials at the time of submission; photocopies of such material may be included. Authors are responsible for obtaining all illustrative materials and permissions for reproduction, and for writing captions.

Authors of accepted manuscripts will receive two copies of the issue in which the article appears, and twenty-five offprints.

\section{Manuscript Preparation}

We use the 14th edition of The Chicago Mamual of Style (1993) and spell and hyphenate words according to Webster's Ninth New Collegiate Dictionary.

The journal encourages authors to use gender-neutral prose in all cases where it is not anachronistic to do so; male nouns and pronouns should not be used to refer to people of both sexes. We use the day-month-year form for dates, as 11 Feb. 1998. Double quotation marks should be used for joumal titles and direct quotation; single quotation marks are used for quoted material inside quotations.

\section{Sample Citatiox Forms}

Book: Alfred D. Chandler, Jr., The Visible Hand: The Managerial Revolution in American Business (Cambridge, Mass., 1977), 321-22.

Journat: Charles Cheape, "Not Politicians but Sound Businessmen: Norton Company and the Third Reich," Business History Revieu 62 (Autumn 1988): 444-66.

Vote that we do not include the publisher in book citations. We do not use loc. cit., op. cit. or idem., but ibid. (not italicized') may be used. 
. 